\title{
Study on the path of Integration use of Land Resource elements under the background of Rural Revitalization
}

\author{
Hong Tang ${ }^{1}$, Changpin $\mathrm{Ji}^{2}$, Yan Zhao ${ }^{1}$ \\ ${ }^{1}$ Shanghai Urban Construction Vocational College, Shanghai, 200438, China \\ ${ }^{2}$ East China University of Technology, Jiangxi Nanchang,330105China
}

\begin{abstract}
At present, with the rapid development of urban-rural integration, the problems of land fragmentation in rural areas, such as low land use rate, poor economic benefits, many production conflicts and disputes, land distribution difficulties and other negative effects, continue to appear, and the rural economic development is very severe. Based on this, this paper mainly studies the path of land resource integration, studies the reform of land system in various aspects, such as land circulation system, homestead reform, land acquisition system and other specific systems, and studies the specific path of land resource integration, so as to promote the land utilization rate, promote the rapid development of population industry and its development The increase of farmers' income.
\end{abstract}

\section{Introduction}

Beneficial to the people's livelihood, comrade Xi Jinping pointed out in his major reports that the fundamental issue of the relationship bet nineteen ween the people and the people's livelihood is the "three rural issues", namely, agriculture, rural areas and farmers. Only by solving the problem of "three rural issues" and taking it as the priority among priorities can we better implement the strategy of Rural Revitalization [10].

\section{The dilemma of land resources utilization under the background of Rural Revitalization}

\section{1 hollow Homestead}

Under the background of rural revitalization, with the rapid development of urbanization, the main young rural labor force to work in the city, which directly leads to the phenomenon of "hollowing out" of villages and the aging of rural population. Moreover, with the large number of young people entering the city from rural areas, it leads to the "hollowing out" of residential land. These problems are mainly reflected in the long-term idleness of a large number of housing Serious waste of homestead and so on. According to the research of Wang Liangjian and others, 1238 survey data were collected by questionnaire survey method, and the data were calculated. The results showed that the average hollow rate of homestead was $29.14 \%$.
2.2 The phenomenon of abandoning cultivated land and abandoning wasteland was aggravated

The main reasons for land abandonment are as follows: first, the benefit of land is low: farmers feel that the input is large but the income is small, so many farmers leave the land idle; second, the serious shortage of labor force: most of the young people go out to work and stay in the countryside, only some elderly people over 60 years old, naturally have no energy to plant; third, poor agricultural infrastructure: a lot of land The oldest facilities still in use have not been updated; fourth, the mode of agricultural production is relatively backward: the backward areas are still planted artificially, but at the present level of development, mechanization can completely replace it.

\section{The connotation and necessity of land resources integration under the background of Rural Revitalization}

\subsection{Connotation of land resource elements integration}

Under the background of rural revitalization, the three key elements of population, land and industry affect the rural social and economic development. Among them, land resources provide resource support for Rural Revitalization and play a fundamental role in this respect, and land resources play a diversified role in production, life and ecological space. As a basic element of regional development, land resources also promote the transformation of different rural industrial development modes, thus promoting the development of regional 
economy.

\subsection{The necessity of land resource elements integration}

Land resources, as the most important element in the three elements of rural revitalization, promote the integration of land resources through cross regional transfer, and then promote the industrial scale development. Taking shangtouzha village, Chang'an Township, Ganzhou District, Gansu Province as an example, the village has transferred $3100 \mathrm{mu}$ of land and transferred more than $10000 \mathrm{mu}$ of land in Linze, Dunhuang and other cities and counties across the region, which has led to the large-scale and professional development of the village's vegetable industry. Since 2008, the village has vigorously developed the vegetable industry. In order to solve the problems in the development of the vegetable industry, the village has set up a professional vegetable cooperative. In addition, the cross regional circulation, the villagers rent the land according to the voluntary principle, with the rent of about 600-780 yuan per mu.

\section{Analysis of the interest demands of the stakeholders in the integration of land resources elements}

In the process of land resources integration and utilization, different stakeholders, including government, enterprises and the public, play different roles and have different interest demands. For the government, the main interest demands of the government are how to ensure food security and ensure that land value-added can generate income; the main interest demand of the organization is to pursue profit maximization; the main interest demand of the people is how to obtain income and employment opportunities through land, so as to improve the living standard and quality of life.

\subsection{Analysis of the government's interest demands}

\subsubsection{Ensuring food security}

Only when the government is responsible for ensuring food security can the utilization efficiency of cultivated land be taken seriously. However, there is still a lack of institutional incentives to ensure food security. Farmers have no enthusiasm for planting grain, which leads to waste of cultivated land and low utilization rate of land resources. As a result, the responsibility of ensuring food security falls on the head of the government. As far as the government is concerned, it is expected that the number of construction land indicators will increase if it does a good job in ensuring food security. In order to obtain more indicators, it must save the area of cultivated land; at the same time, when the cultivated land area decreases, it can not affect the food security. This makes the government in the use of arable land more meticulous, to maximize the use of land resources; food security if not done well, it is difficult to obtain more construction land indicators, on the contrary, can only explore the potential of cultivated land, and then achieve food security, promote the deep use of cultivated land.

\subsubsection{Promoting rural economic development}

For rural areas, the local government is the main driving force to promote its economic development. The local government in rural areas should make forward-looking planning in rural long-term planning, because it will directly affect the speed of rural economic development. In terms of planning, if the government wants to promote the development of rural economy, it must change the growth mode, use science and technology to drive the rural economic development, and the government should fulfill its functions with the goal of stable rural development and increasing farmers' income. In terms of market management, the local government should strictly plan and organize the market when strengthening the construction of market facilities, so as to give full play to the role of the market, so as to obtain economic benefits and promote the development of rural economy. On the other hand, the local government should recruit talents to expand the market of capital, talents and technology to promote its development.

\subsection{Analysis of organization's interest demands}

The first is to continuously promote the differential land price policy of industrial land. For the advanced equipment manufacturing industry, high-tech industry, strategic emerging industry, and industrial enterprise performance evaluation of class $\mathrm{A}$ and other priority development and conservation intensive projects, the land price correction coefficient is adopted to revise and float down to determine the transfer starting price, and further release the policy dividend.

The second is to encourage the implementation of flexible transfer period of industrial land. According to the types and characteristics of the industry, determine the 1050 years period, flexibly determine the transfer period of industrial land, and reduce the initial cost of industrial enterprises. At the same time, we can encourage the implementation of the mode of "lease first and then transfer", develop and develop the lease term according to the contract, and provide the land with negotiated transfer mode after the expiration of the lease term.

\subsection{Analysis of pople's interest demands}

Guarantee the free transfer of land, In the case of no operation, the contracted land can be transferred to realize the value-added income of land property rights, which should be what most farmers are happy to see. However, it is not easy to realize this wish. Many farmers worry about one thing or another: first, they are afraid of signing long-term contracts because they are worried about future land rent increases, or because they are afraid to avoid risks. As some farmers admit, "if you sign a 10-year contract at a time, who knows if it will be worthwhile in 
the future?" This worry is the main reason that most of the circulation contracts are less than 5 years, especially 1-3 years. Another reason for not signing long-term circulation contracts is to avoid risks and worry that there will be a retreat when employment and entrepreneurship in cities are unsatisfactory. Because if you sign a long-term contract, if you can't stay in the city, there's no way out.

\section{The specific construction of integration path of land resource elements under the background of Rural Revitalization}

Land resource element is the most important element among the three elements of rural development. If the protection of land is the common interests of the people, then this interest is more directly reflected in the farmers. On the one hand, "economic development" can only rely on land; on the other hand, from the perspective of China's modernization construction, the state needs to boldly innovate the way of land resource integration on the basis of natural law, economic law and social development law. There is no doubt that the implementation and implementation of new rural construction land planning, we must implement the people-oriented standards, planning arrangements, full cooperation, sustainable and scientific development. The first is to integrate land resources in the construction of new rural areas, and promote the civilized development mode of urban and rural social production, ecology and affluence. Second, we should establish the principle of respecting and protecting farmers' land and interests and distributing the rural land income to farmers. Third, the new rural planning should be treated as an important part of urban regional development planning. Fourth, we should gradually promote the reform of the land system in accordance with the requirements of urbanization, marketization and industrialization.

\subsection{Stable ownership}

Extension of land contract period, Under the collective ownership of rural land, the land contract system is directly related to farmers' income and agricultural production efficiency, and has become the basis of many policies, and the contract period policy is the core of the contract system. Since the household contract responsibility system was implemented in 1978, the contract period of cultivated land has been adjusted twice in 15 years and 30 years. With the help of the original contract period policy, China has made great economic achievements in "steady progress of agricultural modernization and grain production capacity reaching 1.2 trillion $\mathrm{kg}$ ", which fully proves the great significance of stabilizing the contract relationship for agricultural development and Rural Revitalization. However, due to the fuzzy boundaries of farmland rights and the changes of rural population environment, the previous contract period policy has always been difficult to overcome the contradiction between human and land and the lack of rural development momentum, which will hinder the promotion of Rural Revitalization Strategy in the new period to a certain extent.

\subsection{Planning guidance}

Scientific planning is the premise of optimizing the structure and layout of rural land use and ensuring the overall development of rural land. In order to promote rural revitalization, we should first strengthen the planning consciousness, improve the planning system, and give full play to the role of planning in guiding, guiding and controlling. At present, the key task is to do a good job of village land use planning research, preparation, implementation and supervision.

1) Strengthen planning guidance and effectively guide rural revitalization of all kinds of development land

2) Strengthen investigation and research, scientifically arrange the structure and scale of rural development land

3 ) Strengthen overall planning and integration, and reasonably arrange the layout and timing of rural development land

4) Strengthen the supervision of implementation and earnestly enhance the seriousness and stability of village level planning

\subsection{Increase farmers'income}

Increasing income is the specific goal of the integration path of land resource elements. After the land integration, the land becomes neat and the quality of land is obviously improved. Farmers do not need to cultivate the land as before, but turn to mechanized farming. Farmers' management has really realized the scale. Through the large-scale operation, the farmers can also develop the characteristic agriculture in the countryside, establish the local unique farmhouse, and develop their own rural characteristics Many tourists are attracted to experience the tourism with rural characteristics, which promotes the income of farmhouse enjoyment. In some areas, the mechanism of "party members bringing wealth" is established to increase farmers' income, adhere to recruiting party members among capable people to become rich. Meanwhile, the party members and the masses take the form of "one helping one" and "one helping more" to drive the masses to develop industries, so as to realize "one household, one area and one village". At the same time, the construction and development mechanism takes the form of "Party branch + company + cooperative + farmer" To set up the village Tongfu agricultural development company to transfer the whole village's land and increase the corresponding income of farmers.

\section{Conclusion}

Under the background of rural revitalization, there are many problems in land resources, which need to be solved urgently. These all depend on the integrated utilization of land resources. The integration of land resources elements 
includes not only the land integration within the region, but also the land integration among regions: the regional land circulation promotes the industrial development and reflects it by reasonably planning the land resource space; the inter regional land integration integrates the land resources through the cross regional transaction between different indicators and the transfer between different regions. The path construction process of land resource elements integration includes the extension of land contract period, the protection of farmers' land rights and interests, the increase of farmers' income, and the reform of land system. As we all know, the most effective way to improve the rural land contract right system is to implement the rural strategy. From ancient times to the present, land is a tool for farmers to rely on for survival, and also provides a driving force for social development. Therefore, to give full play to the advantages of land and turn it into economy, so that farmers can increase their income, which has become the key to rural revitalization.

\section{Reference}

1. Zuoji Dong. Difficulties and solutions of rural land system reform [J], land economy research, 2017 (1)

2. Shouying Liu, Xuefen Xiong g. Implementation and institutional supply of Rural Revitalization Strategy in China [J]. Political economy review, 2018 (4)

3. Jiali Gao. Village construction and development planning based on comprehensive land consolidation under the background of Rural Revitalization [D]. Zhejiang University, October 18, 2019

4. Yue Sun. Research on rural land idle under the strategy of Rural Revitalization [J]. Southern agricultural machinery, 2018,49 (21): $77+82$

5. Yanying Li, Zengyuan Li. Challenges and Countermeasures of rural land use from the perspective of Rural Revitalization [J]. Journal of Qingyuan vocational and technical college, 2019, 12 (01): 41-47

6. Hualou Long, Yingnan Zhang, Tu shuangshuangshuang. On land consolidation and Rural Revitalization [J]. Acta geographica Sinica, 2018,73 (10): 1837-1849

7. Guangfei Song. On the problems and government behavior in rural land circulation $[\mathrm{J}]$. Peasant staff, 2019 (21): $27+62$

8. Qin Zhang, Kaiyu Wang, Bingqi Zhao. Research on government positioning in rural residential land transfer -- Based on stakeholder game analysis [J]. Journal of Ningbo University (Humanities), 2018,31 (04): 65-69

9. Huimin Cai. Sorting out rural land circulation policies under the background of Rural Revitalization [J]. Agricultural economy, 2018 (10): 102-104

10. Chuansheng Cheng. Problems and Countermeasures of farmers' land rights protection under the background of Rural Revitalization [J]. Modern agricultural science and technology, 2019 (24): 255 258
11. Xuesong Kong, Jing Wang, Zhifeng Jin, Lingli Ying. Transformation and innovation of rural land consolidation for Rural Revitalization [J]. China land science, 2019,33 (05): 95-102

12. Qingbin Liu. The path of protecting farmers' land rights and interests from the perspective of Rural Revitalization [J]. Shandong economic strategy research, 2019 (06): 62-64

13. Bianfan Lai. Research on the factors and Countermeasures Affecting the development of agricultural industry under the background of Rural Revitalization $[\mathrm{J}]$. Rural economy and science and technology, 2019, 30 (01): 15-17 